\title{
Tribunal simulado: efeito da ordem das teses e do antecedente do réu ${ }^{1}$
}

\author{
Ronaldo Pilati ${ }^{2}$ \\ Universidade de Brasília, Brasília-DF, Brasil \\ Alexandre Magno Dias Silvino \\ Faculdade de Ciências Sociais e Tecnológicas, Taguatinga-DF, Brasil \\ Marco Akira Miura \\ Lucas Soares Caldas \\ Universidade de Brasilia, Brasília-DF, Brasil
}

\begin{abstract}
Resumo: Dois estudos experimentais de tribunal simulado tiveram como objetivo avaliar o efeito do antecedente criminal do réu e da ordem de apresentação das teses de acusação e defesa na deliberação de jurados. No primeiro foi realizado um delineamento fatorial 2 (ordem das teses) X 2 (perfil do réu) do qual participaram 123 estudantes, que assistiram a um julgamento simulado gravado em vídeo. Os resultados indicaram que houve tendência de condenação e que a ordem e o perfil não influenciam na deliberação, mas que o desempenho dos atores do vídeo exerceu efeito significativo na deliberação. No segundo estudo o caso foi apresentado de forma textual, sem apoio do vídeo. Apenas a variável perfil fez parte do delineamento e participaram do estudo 54 estudantes. Os resultados indicaram que o perfil não exerceu efeito na deliberação, mas a amostra tendeu a absolver o réu. Processos sócio-cognitivos precisam ser melhor investigados em estudos futuros.
\end{abstract}

Palavras-chave: psicologia social, psicologia forense, estereótipos, memória.

\section{Mock trial: debates order and defendant antecedents}

\begin{abstract}
Two mock trial studies had the purpose of evaluate the effect of defendant criminal antecedents and the debate order over the juror deliberation. On the first study a factorial design of 2 (debate order) X 2 (defendant antecedent) was conducted and 123 students watched a video mock trial. The results show a sample tendency to find the defendant guilty and the debates order and the defendant profile had no influence on jurors' decisions. However, the prosecutor and attorney performance was significantly correlated with the jurors' decision making. The second study had the defendant antecedents as the independent variable and was done with the trial presentation with a text transcription. The sample was 54 students. The results demonstrate that defendant profile had no effect over the juror' decisions, but the sample tendency was to find the defendant not guilty. Socio-cognitive processes have to be more investigated in future studies.
\end{abstract}

Keywords: social psychology, forensic psychology, mock trial, stereotypes, memory.

\section{Tribunal simulado: efecto del orden de las teses e del antecedente del reo}

Resumen: Dos estudios fueron desarrollados con el objetivo de evaluar la influencia del antecedente criminal del reo y de la orden de presentación de las teses en la deliberación de los jurados. Participaron del primer tribunal simulado 123 estudiantes en un delineamiento factorial 2 (orden de presentación) X 2 (perfil del reo). Los resultados indicaron que hubo una tendencia de condenación y que el orden de los debates y el perfil del reo no influyeron en la decisión de los jurados. En el segundo estudio el juzgamiento fue presentado en texto y solo la variable del perfil del reo fue manipulada. Participaron 54 estudiantes. Los resultados indicaron que el perfil del reo no ejerce influencia en la deliberación, pero hubo una tendencia de no condenación. Es necesario otros estudios para el teste de la influencia de los procesos socio-cognitivos en la decisión de los jurados.

Palabras clave: psicología social, psicología forense, tribunal simulada, estereotipos, memoria.

A psicologia e as ciências jurídicas possuem diversas interfaces de pesquisa e atuação profissional. Dentre elas

1 Apoio: UnB e FACITEC. Os autores agradecem a participação dos alunos André Carvalho, Adriano Sampaio de Souza, Annelise Thieli Soares, Luis Fernando Resende Arantes, Tatianne Hellen A. de Oliveira, Áureo Queiroz de Souza, Ajileu José de Souza, Josiane Gonçalves dos Reis, Leonardo Graciliano da Cruz, Juliana Souza Guedes; e dos professores Sérgio Santos (coordenador da Assessoria de Comunicação da FACITEC) e Wagno Antônio de Souza (Dr. Juiz de Direito) pelo auxílio na preparação dos procedimentos experimentais e na coleta de dados em diversas fases do estudo, entre os anos de 2007 e 2009.

2 Endereço para Correspondência:

Ronaldo Pilati. Universidade de Brasília. Instituto de Psicologia. Departamento de Psicologia Social e do Trabalho. Instituto Central de Ciências, Ala Sul, Campus Universitário Darcy Ribeiro, Asa Norte, CEP 70.910-900 Brasília, DF.E-mail: rpilati@unb.br destaca-se aquela que diz respeito à psicologia da deliberação legal, na qual o interesse principal de investigação centra-se em compreender como os operadores do direito efetuam a tomada de decisões a partir da consideração dos chamados aspectos extra-legais (aqueles que vão além das parametrizações e definições dadas pela legislação vigente e pela interpretação desta legislação feita pelos operadores). A psicologia da deliberação legal objetiva compreender como os processos psicológicos exercem influência sobre a tomada de decisão dos operadores do direito.

A psicologia da deliberação legal recebe aportes teóricos e metodológicos de diferentes modelos como os da psicologia cognitiva e da psicologia social. A relevância da contribuição dos modelos sócio-cognitivos pode ser 
verificada pela grande quantidade de revisões teóricas e relatos de pesquisa empírica, que utilizam esse referencial teórico-metodológico, feitos em diversos países (Diamond \& Rose, 2005; Ellsworth \& Mauro, 1998; Kerr \& Bray, 2005; Köhnken, Fiedler, \& Möhlenbeck, 2001; Levett, Danielsen, Kovera, \& Cutler, 2005; Pennington \& Hastie, 1992; Studebaker \& Penrod, 2005; Tyler \& Jost, 2007; Williams \& Jones, 2005). O presente trabalho adota uma perspectiva empírica da psicologia social experimental para o teste de hipóteses de fatores sócio-cognitivos sobre a tomada de decisão de jurados, operadores de deliberação na alçada do tribunal do júri brasileiro.

Como asseveram Pilati e Silvino (2009), ainda que exista muita produção científica na psicologia social da deliberação legal em outros países, a aplicação dos conhecimentos produzidos em outras nações é virtualmente impossível, principalmente por dois motivos: (a) diferenças dos procedimentos jurídico-processuais entre os países; e (b) diferenças culturais entre as nações. Em uma agenda da área, Pilati e Silvino lograram encontrar apenas um trabalho empírico que buscou compreender o efeito de aspectos psicossociais na tomada de decisão de jurados no Brasil (Vainsencher \& Farias, 1997). Essa ocorrência singular sugere a necessidade de se produzir conhecimento empírico sobre a psicologia da deliberação legal dos operadores do direito no Brasil. O estudo ora apresentado se configura em uma contribuição nesse sentido.

O estabelecimento de uma linha de investigação na psicologia da deliberação legal no contexto nacional exige a identificação de variáveis relevantes, considerando-se os aspectos jurídicos processuais brasileiros. A partir de uma análise do Código de Processo Penal Brasileiro (Brasil, 2007) alguns elementos são evidenciados como centrais nos rituais de julgamento do tribunal do júri. A fim de permitir a execução de um projeto de pesquisa empírica neste contexto, foram selecionados dois elementos relevantes do código e que dizem respeito a aspectos extralegais diretamente relacionados a processos sócio-cognitivos. O primeiro diz respeito à antecedência criminal do réu em julgamento e o segundo à ordem de apresentação das teses de acusação e defesa.

Esses dois elementos suscitam aspectos da literatura de tomada de decisões. O primeiro versa sobre a aplicação de um estereótipo ao réu, o que pode estar diretamente relacionado à forma pela qual o jurado inferirá as relações entre os fatos relatados no julgamento e, posteriormente, tomará sua decisão sobre a deliberação. O segundo aspecto está associado aos efeitos de primazia e recência da memória, pois as ordens dos debates estão associadas a estes elementos. Vale ressaltar que o processo penal brasileiro prevê que apenas os elementos apresentados durante o processo de julgamento devem ser considerados para a deliberação do jurado, o que implica que condenações anteriores não deveriam ser relevantes para um processo em particular. O outro elemento legal, concernente ao debate das teses, está alicerçado no princípio de favorecimento do réu (in dubio pro reo) e, por este motivo, define que a tese da defesa deva ser a última a ser apresentada, de forma a garantir maior proximidade entre a apresentação desses argumentos e a deliberação do júri.

Diante destes elementos o presente trabalho tem como objetivo avaliar o efeito que a presença de antecedentes do réu e a ordem de debates das partes têm sobre a deliberação de jurados em júris simulados. Também foram objetivos deste trabalho: avaliar o efeito da estereotipização sobre a atribuição de responsabilidade que os jurados fazem do comportamento do réu e a recordação dos jurados sobre os argumentos das partes apresentados nos debates do julgamento.

\section{Processos sócio-cognitivos para tomada de decisões: estereótipo, atribuição de causalidade e memória}

Um estereótipo pode ser definido como uma estrutura mental na qual estão armazenados os conhecimentos, crenças e expectativas do observador em relação a algum grupo humano (Fiske, 1998; Fiske \& Taylor, 2008; Operario \& Fiske, 2001; Pereira, 2002; Quinn, Macrae, \& Bodenhausen, 2003). O conceito de estereótipo tem sido constantemente pesquisado na literatura de psicologia social como antecedente a processos de julgamento social e de tomada de decisões relativas a indivíduos ou grupos de indivíduos (Fiske, 1998; Fiske \& Taylor, 2008). A partir dos modelos compreensivos da cognição social, sobre a forma de processamento e aplicação de conhecimentos que os indivíduos fazem de objetos sociais, é possível compreender que esta estrutura mental exerce influência sobre os mecanismos de tomada de decisões dos indivíduos sobre outros indivíduos.

Pereira (2002) aponta que é relevante a diferenciação entre estereótipo e estereotipização, pois este último referese à aplicação de um julgamento estereotipado em relação a um indivíduo, de forma a apresentar o indivíduo como portador de características disposicionais comuns ao grupo de pertencimento. Se os observadores estereotipizam indivíduos classificados em determinados grupos sociais, seria de se esperar que os mesmos também considerem comuns ou freqüentes certos comportamentos por parte de indivíduos classificados em determinados grupos sociais. Algumas evidências da literatura de psicologia social têm apontado que o estereótipo pode estar associado à atribuição de características disposicionais e a comportamentos específicos no indivíduo (Kunda \& Thagard, 1996). Evidências como essas sugerem que o mesmo processo pode ocorrer no contexto de deliberação legal. Assim, uma condenação prévia, por crime agressivo, pode estar associada à atribuição de traços agressivos ao réu, o que influenciaria diretamente a deliberação do jurado.

A estereotipização está associada a outro processo no desenvolvimento da decisão do jurado, a atribuição de causalidade. De acordo com Trope e Cooper (2003) a percepção social pode ser definida como a maneira pela qual coletamos informações sobre o mundo social ao nosso redor e como explicamos o comportamento dos atores sociais dentro do 
contexto social. Modelos clássicos de atribuição distinguem duas dimensões básicas nas quais o lócus de explicação do comportamento se dá: interno e externo ao indivíduo. A atribuição interna significa que o indivíduo lança mão de características disposicionais do alvo da percepção para a explicação do seu comportamento. A atribuição externa indica que o indivíduo lança mão de aspectos da situação na qual o comportamento ocorreu (Dela-Coleta \& Dela-Coleta, 2006). Em um contexto de julgamento com a apresentação do antecedente criminal do réu é factível hipotetizar que a estereotipização levaria a aplicação de atribuição interna ao comportamento de homicídio em julgamento, o que aumentaria a chance de condenação na deliberação do jurado.

No caso de um processo de julgamento, em que a defesa e a acusação têm a função de apresentar evidências sobre o comportamento de um réu, o processo de atribuição exerce papel importante, uma vez que influencia a percepção das causas do comportamento do réu. Isso propicia justificativa para a deliberação, funcionando, então, como aspecto relevante da decisão legal. A situação de julgamento possui, ainda, uma particularidade, pois nesta situação social os jurados mantêm alta motivação e concentração na apresentação das evidências sobre o comportamento do réu, o que implica em um processo de atribuição de causalidade cuidadoso e, conseqüentemente, mais fidedigno (Anderson, Krull, \& Weiner, 1996).

Estudos em psicologia da deliberação legal apresentam evidências de que o processo de codificação e organização das informações de um julgamento na memória de um jurado é um aspecto relevante para que se possa desenvolver a história sumarizada do julgamento. A literatura tem apontado que este processo de transformação dos argumentos e evidências apresentadas em um sumário de informações é crucial para a tomada de decisão do jurado (Köhnken e cols., 2001; Pennington \& Hastie, 1992). Por isso, compreender como a memória está organizada do ponto de vista estrutural e funcional é relevante para entender como e quais informações são recuperadas no momento da decisão.

São muitos os modelos e paradigmas para o estudo da memória. Dado que o recorte e objetivo do presente estudo estão voltados mais aos fenômenos relacionados ao processamento cognitivo, optou-se pelo modelo Adaptive Control of Thought (ACT) proposto por Anderson (Anderson, 1983b), por ser um modelo de arquitetura cognitiva integrada (Anderson, Bothell, Byrne, Douglass, Lebiere, \& Qin, 2004) como um todo e dada sua robustez, considerando os estudos recentes acerca da associação com modelos neurológicos (Anderson, Fincham, Qin, \& Stocco, 2008).

Nesse modelo, a memória pode ser compreendida atuando como distribuída em redes, sugerindo que a informação é armazenada em traços (unidades cognitivas) que estão ligados entre si, podendo ser ativados ou não. Assim, pode-se propor que o modelo mental (ou a construção da história sumarizada do julgamento) ocorre por meio de um padrão de ativação (Anderson \& Pirolli, 1984) constituído por um conjunto de traços de informação recuperados na memória de longo prazo e ativados na memória de trabalho (Anderson, 1983b).

Há alguns efeitos ou fenômenos ligados à memória e ao processo decisório que são particularmente relevantes para entender o efeito da ordem em que a promotoria e defesa apresentam seus argumentos. A utilização de heurísticas, atalhos mentais que tornam mais leve o processamento cognitivo (Gigerenzer, Todd, \& Group, 1999), é fundamental para a deflagração de um padrão de ativação na memória de trabalho. O preço para esta economia é o aumento na probabilidade de erros e viéses no julgamento. Diferentes heurísticas podem estar envolvidas no processo de julgamento de um jurado, em particular as heurísticas de representatividade e disponibilidade têm maior chance de ocorrência. A heurística de representatividade está relacionada com a construção de estereótipos, pois se trata do julgamento em função de um modelo existente. A heurística da disponibilidade refere-se à influência das informações ativas na memória no processo de evocação.

As heurísticas podem se relacionar com os efeitos de primazia e recência. $\mathrm{O}$ efeito de primazia é a facilidade de recordação dos eventos que ocorreram primeiro quando apresentados serialmente. $\mathrm{O}$ efeito de recência refere-se à facilidade de evocação dos eventos mais recentes (Matlin, 2004). O ACT (Anderson, 1983a) possui um conjunto de pressupostos que explicam o processo cognitivo no seio desse modelo. Assim, dado o terceiro pressuposto do ACT que sugere a heurística como elevando a probabilidade de ocorrência de um padrão de ativação específico, aliado ao quinto pressuposto de que esse padrão é contínuo em função do tempo e ao sexto pressuposto de que o ambiente produz a fonte para a manutenção desse padrão, é factível acreditar que as heurísticas e o estereótipo do réu (figura presente durante todo o julgamento) são fatores essenciais na tomada de decisão nesse contexto. Da mesma forma, a ordem de apresentação do caso pode influenciar a probabilidade de recuperação e o processo decisório.

Finalmente, os efeitos de interferência proativa e retroativa pressupõem, respectivamente, que as pessoas têm dificuldade de evocar material novo dado que o antigo interfere na nova lembrança e têm dificuldade de evocar material antigo porque o novo influencia a recordação (Matlin, 2004), o que se relaciona com o nono pressuposto do ACT que sugere que quanto maior é a deflagração de um padrão, maior a chance de recuperá-lo novamente pela força da associação entre as unidades cognitivas. Da mesma forma que os efeitos anteriores, pode ser que apresentar as evidências e o caso, primeiramente, possa promover uma interferência na facilidade de recuperação das informações (e vice-versa) e que isso influencie o processo decisório. Considerando que a lei brasileira prevê que os jurados não podem conversar entre si sobre o julgamento, esses efeitos não podem ser minimizados pelo contato social, no qual os colegas poderiam recordar partes importantes para o caso. 
A literatura de psicologia da deliberação legal já apresentou modelos relevantes para se compreender o processo de tomada de decisões de jurados. Pennington e Hastie (1988) argumentam que os modelos de processamento de informações, presentes na literatura nos anos 1980, não eram adequados para predizer o veredicto de jurados, tendo em vista a complexidade da tarefa de deliberação legal. Segundo as autoras os modelos de tomada de decisões não conseguiam captar a complexidade da tarefa de decisão legal porque partiam de princípios equivocados, como a atualização contínua das evidências apresentadas no julgamento, a ausência de interdependência entre as evidências, o raciocínio probabilístico sobre as situações de incerteza, entre outros elementos. Para superar a lacuna, elas propuseram um modelo denominado 'Modelo da história em decisões judiciais'. Segundo o modelo, os jurados constroem um sumário das informações (argumentos, evidências, relatos testemunhais) fornecidas durante o julgamento e com base nestas informações os jurados constroem modelos causais de explicação das evidências apresentadas durante o julgamento.

Estas histórias construídas pelo jurado são constituídas por conjuntos de eventos e relações causais referidas no julgamento, e também por inferências feitas quase inteiramente pelos jurados. Independentemente da fonte, tais inferências servirão para preencher a estrutura de episódios da estória sumarizada. De acordo com a teoria, a representação mental construída pelo jurado se constituirá pela coordenação e combinação de três tipos de informação: (a) informações específicas do caso, dadas ao longo do julgamento; (b) conhecimento prévio sobre eventos similares ao que deve ser julgado; e (c) expectativas gerais sobre o que constitui uma história completa (a idéia de que as ações humanas são motivadas por objetivos). Com esta pressuposição, o modelo prescreve que o jurado não apenas constrói uma história do caso, mas várias possíveis histórias alternativas e aquela que melhor se ajusta na explicação das evidências apresentadas durante o julgamento será a base utilizada pelo jurado para o seu veredicto.

Um dos aspectos explicativos necessários de serem evidenciados na história sumarizada é aquela relativa ao comportamento do réu e é nesse contexto que o processo de atribuição joga seu papel. O uso de elementos explicativos disposicionais pode ser uma das estratégias utilizadas pelos jurados para construir um modelo causal de explicação das evidências. A atribuição de agressividade do réu serviria para se explicar a conduta agressiva pela qual ele está em julgamento. Assim, o conhecimento prévio e o estereótipo que define um tipo de comportamento esperado ou compatível com perfil do réu pode ser um elemento importante para a tomada de decisões do jurado. Já no concernente ao processo de armazenamento das informações na memória pressupõe-se que a ordem de apresentação das teses surte um efeito na maneira como a história sumarizada é construída, resultando em efeitos específicos na deliberação dos jurados. Desta forma seria possível se depreender as seguintes hipóteses de trabalho:
$\mathrm{H}_{1}$ - Jurados na condição experimental em que a tese da defesa foi apresentada por último tenderão a absolver o réu. $\mathrm{H}_{1 \mathrm{a}}-\mathrm{Os}$ jurados tenderão a ser mais acurados na recordação dos argumentos apresentados por último durante o julgamento. $\mathrm{H}_{2}$ - Jurados na condição experimental em que o réu possui perfil com antecedentes criminais tenderão a condenar o réu.

$\mathrm{H}_{2 \mathrm{a}}$ - Jurados na condição experimental em que o réu possui perfil com antecedentes tenderão a atribuir o comportamento do réu a fatores internos.

\section{Estudo 1}

Este estudo constitui-se em um estudo experimental de simulação de um julgamento com delineamento fatorial 2 (perfil do réu: com antecedentes $\mathrm{X}$ sem antecedentes) X 2 (ordem dos debates: início promotoria $\mathrm{X}$ início defesa). $\mathrm{O}$ caso utilizado no julgamento simulado trata-se um caso real de homicídio julgado em tribunal do júri, ocorrido em uma cidade do Distrito Federal. Este estudo foi desenvolvido seguindo princípios de ética em pesquisa com seres humanos definidos pelo Conselho Nacional de Saúde e pelas diretrizes para ética na pesquisa da Associação Americana de Psicologia. Garantiu-se participação voluntária, garantia de sigilo e anonimato dos participantes. O consentimento livre e esclarecido foi realizado de forma oral antes da apresentação dos procedimentos de pesquisa, de forma a garantir compreensão completa dos participantes sobre objetivos do estudo, característica e implicações dos procedimentos da pesquisa. Apenas após a anuência dos participantes voluntários é que se iniciava o procedimento de pesquisa.

\section{Método}

\section{Participantes}

Participaram 123 estudantes universitários que cursavam a disciplina de metodologia científica. A participação voluntária na pesquisa foi dada como atividade extra, sem vínculo com os créditos da disciplina. Os participantes, em sua maioria do sexo feminino $(53,7 \%)$, variaram entre $17 \mathrm{e}$ 53 anos de idade $(\mathrm{M}=23,1 ; \mathrm{DP}=6,7)$. A maioria dos participantes $(n=109)$ cursava o primeiro semestre de comunicação social $(n=69)$. Apenas três afirmaram ter participado como jurado em um julgamento real.

\section{Instrumentos}

$\mathrm{O}$ instrumento utilizado para a coleta dos dados foi composto por quatro páginas divididas em: (a) apresentação do perfil do réu; (b) ficha de deliberação; (c) escala de atribuição de causalidade; (d) escala de desempenho das partes; (e) questionário sócio-demográfico; e (f) medida de memória dos argumentos das partes.

A primeira parte, a folha de rosto, continha o texto de apresentação da pesquisa, na qual foram apresentados os termos de participação voluntária, a garantia de anonimato dos participantes, o tratamento agrupado dos dados. Esta parte 
também continha as instruções do procedimento da pesquisa e para o preenchimento do questionário, bem como a foto do réu com um histórico resumido sobre o mesmo. As descrições, bem como a foto do réu, foram obtidas por meio de um estudo-piloto.

$\mathrm{Na}$ segunda parte, ficha de deliberação, o participante deveria julgar três quesitos, na forma como é descrito no código de processo penal. Os quesitos eram afirmações sobre o crime e seus agravantes a que os participantes deveriam responder se concordavam com cada uma delas: (a) o réu efetuou os disparos de arma de fogo produzindo os ferimentos que causaram a morte da vítima; (b) o crime foi cometido por motivo torpe de vingança; e (c) o réu atingiu a vítima pelas costas, não dando chance de defesa à vítima.

$\mathrm{Na}$ terceira folha, havia 1) a escala de atribuição de causalidade, 2) a escala de avaliação do desempenho das partes e 3 ) o questionário sócio-demográfico. A escala de atribuição de causalidade continha oito itens associados a uma escala de diferencial semântico, com uma extremidade de internalidade e outra de externalidade. Escores mais baixos significam atribuição interna e escores mais altos atribuição externa. A análise fatorial indicou uma estrutura unifatorial, sendo que seis itens obtiveram cargas fatoriais superiores a 0,35 com índice de consistência interna aceitável $(\alpha=0,62)$.

O desempenho das partes (defesa e acusação) foi medido por uma escala de sete itens para cada parte, associados a uma escala Likert de sete pontos de concordância. Os itens para ambas as partes avaliavam os mesmos quesitos, como coerência do discurso, clareza na fala e convencimento dos argumentos apresentados. As análises fatoriais indicaram que a escala de desempenho da defesa teve estrutura unifatorial com cargas variando de 0,76 a 0,91 e excelente índice de confiabilidade $(\alpha=0,93)$ e que a escala de desempenho da acusação teve estrutura unifatorial com cargas variando de 0,76 a 0,90 e excelente índice de confiabilidade $(\alpha=0,93)$.

Ao final do questionário era apresentada a escala de memória sobre o relato do julgamento, que buscou avaliar o nível de retenção das informações apresentadas no tribunal simulado. Os itens da escala foram concebidos a partir da transcrição de partes dos discursos do juiz e dos advogados em asserções factuais ("A arma do crime não foi encontrada"; "A polícia não encontrou o réu quando da sua intimação"). A tarefa do participante era avaliar se a afirmação estava presente nos discursos apresentados no vídeo e, em seguida, avaliar o grau de segurança sobre a resposta dada. Todos os itens apresentados eram afirmações presentes no tribunal simulado. Na versão original, a escala continha 28 afirmações presentes nos discursos apresentados no vídeo, listadas aleatoriamente. Diante dos resultados do estudo-piloto, observou-se que houve diferença na evocação de informações, dependendo da condição estabelecida. Além disso, alguns itens se destacaram dos demais, em número de erros, por possuírem o conteúdo similar ao de outro item. Assim, a escala foi modificada, substituindo-se estes itens por afirmações que não estavam presentes no vídeo. Ao final ela ficou composta por 28 afirmações que deveriam ser respondidas por escala de dicotoma de presença do argumento no discurso das teses.

\section{Material}

Para gravação do tribunal simulado, foi utilizado um sistema de vídeo com câmeras DV e DVCAM, modelo Sony DRSPD-170 e editado em estação de edição não linear com Software adobe para edição e finalização, posteriormente armazenada em DVDs. Para a exibição da gravação do tribunal simulado, utilizou-se uma televisão convencional de 29 polegadas conectada a um leitor de DVD. Os questionários de coleta das respostas de cada sujeito eram padronizados. Neste questionário, também foi impressa a foto do réu com impressora laser monocromática Xerox em alta resolução (1200 DPIs).

\section{Procedimento de coleta de dados}

Aapresentação do caso deu-se por meio de uma gravação do tribunal simulado planejado e executado por estudantes do curso de Direito com experiência em práticas jurídicas. $\mathrm{O}$ caso utilizado no estudo é um caso real, recolhido de um fórum regional, e foi selecionado utilizando o critério de equilíbrio das evidências, de forma a evitar uma evidência crítica para o julgamento do réu. Antes de selecionar os argumentos a serem utilizados no tribunal simulado, todavia, realizou-se um estudo-piloto entre estudantes de Direito com o objetivo de avaliar quais evidências gerariam maior impacto no tribunal simulado. Foram selecionados quatro argumentos para cada parte, de forma a deixá-los equilibrados.

Os argumentos da promotoria foram: (a) o acusado encontrava-se foragido; (b) a irmã do acusado, em seu depoimento, atestou que o mesmo demonstrava obsessão por vingança por acreditar que a vítima teria auxiliado no assassinado do seu irmão; (c) a testemunha ocular afirmou que presenciou o acusado correndo com uma arma na mão no momento do crime; e (d) o laudo cadavérico mostrou que os disparos foram efetuados pelas costas, impossibilitando a defesa da vítima, sugerindo ação premeditada. Os argumentos da defesa foram: (a) o acusado declara não ter cometido o crime, alegações reforçadas pelo depoimento da mãe e da irmã; (b) a arma do crime não foi localizada, de forma que não há prova pericial que vincula o acusado ao crime; (c) por motivos diversos, o acusado não estava presente na data e na hora do ocorrido; e (d) o fato ocorreu em um bar cheio e apenas pessoa uma se apresentou como testemunha.

Para a produção do vídeo, estipulou-se um roteiro de apresentação dos argumentos, de modo que cada argumento foi citado duas vezes. As teses dos advogados foram organizadas de acordo com sua experiência prática no tribunal do júri. Foi produzido um vídeo, que após passar pelo processo de edição, foi gravado em duas versões, uma com a tese da defesa apresentada logo após a descrição do caso pelo juiz e outro com a tese da acusação apresentada inicialmente. Essas duas versões do vídeo garantiram a manipulação da variável ordem de apresentação, como supra-explicado, quando da apresentação do delineamento fatorial do estudo. 
As sessões experimentais foram executadas em salas de aula com tamanho adequado para comportar os grupos experimentais, o experimentador e os demais materiais para projeção do vídeo. As sessões se deram em dias específicos, previamente agendados, ocorrendo na primeira metade do período da aula. Para designação dos participantes entre os grupos experimentais foi realizado um sorteio, mantendo o equilíbrio do número de participantes em cada condição experimental. Então os grupos foram alocados em salas separadas para aplicação das sessões experimentais. Após a separação dos grupos em salas específicas e a distribuição do questionário, leu-se a folha de apresentação da pesquisa, contendo o consentimento livre e esclarecido, contemplando os termos de participação voluntária e, posteriormente a anuência dos participantes, foram lidas as instruções do procedimento da pesquisa.

Para garantir coerência com o CPP, os participantes foram instruídos a não interagirem entre si até o final do procedimento experimental. Antes da exibição do tribunal simulado, leu-se, junto com os participantes, a descrição do réu. O histórico do réu constitui uma das variáveis independentes do estudo - o antecedente penal - cuja manipulação foi feita por meio de dois relatos distintos. Com antecedente criminal: "Elias, 28 anos, solteiro, trabalha como segurança particular e possui $2^{\circ}$ grau completo. É acusado de homicídio duplamente qualificado neste julgamento. Possui ficha criminal. Anteriormente foi indiciado e condenado, em outro processo, em crime de lesão corporal dolosa, na qual se utilizou de um pedaço de madeira para ferir duas vítimas, seus vizinhos." E sem antecedente criminal: "Elias, 28 anos, solteiro, trabalha como técnico de informática e possui $2^{\circ}$ grau completo. É acusado de homicídio duplamente qualificado neste julgamento. Nunca foi preso. Não possui ficha penal."

$\mathrm{O}$ experimentador enfatizou a importância da atenção aos argumentos do vídeo e, os participantes assistiram ao vídeo com a apresentação do caso e os argumentos, conforme a condição. Após a apresentação do vídeo, foi solicitado aos participantes que passassem para a próxima página e respondessem a ficha de deliberação com base no perfil e no vídeo apresentados. De acordo com a instrução dada aos participantes, estes deveriam aguardar até que todos os jurados tivessem preenchido a ficha de deliberação para prosseguir para as próximas etapas.

Não foi estabelecido tempo limite para o preenchimento do questionário. Após o recolhimento dos questionários, foi realizada a contagem dos votos e a apresentação da deliberação para o grupo, obtida pela maioria simples de votos. Para a finalização do procedimento, os pesquisadores responsáveis realizaram o debriefing com seus respectivos grupos, coletando, também, impressões sobre o procedimento e os instrumentos utilizados na pesquisa.

\section{Procedimento de análise dos dados}

Os dados coletados foram analisados por meio de procedimentos descritivos, teste de qui-quadrado, análise de variância (ANOVA) e regressão logística binária. Os dados foram submetidos às análises preliminares para adequação aos pressupostos das análises multivariadas (Hair, Anderson, Tatham, \& Black, 2005; Tabachnick \& Fidell, 2001). Considerando o tipo de análise multivariada empregada e a característica dos dados, não foi necessário nenhum procedimento para alcance de pressupostos.

\section{Resultados e Discussão}

As análises descritivas indicam que houve uma maior tendência a condenação do réu em todas as condições experimentais, com um maior percentual de condenação com o perfil agressivo. Estas informações podem ser observadas na Tabela 1 .

Tabela 1

Quantidade de condenações e absolvições por condição experimental

\begin{tabular}{lcc}
\hline \multirow{2}{*}{ Condição Experimental } & \multicolumn{2}{c}{ Decisão do Jurado } \\
\cline { 2 - 3 } & Culpado & Inocente \\
\hline Com Antecedente/Início Acusação & 19 & 9 \\
Com Antecedente/Início Defesa & 22 & 12 \\
Sem Antecedente/Início Acusação & 16 & 12 \\
Sem Antecedente/Início Defesa & 18 & 15 \\
Total & 75 & 48 \\
\hline
\end{tabular}

Apesar da tendência indicada nos dados, não houve uma associação estatisticamente significativa entre as variáveis $\left(\chi^{2}=1,50 ; g l=3 ; p=0,682\right)$. A mesma ausência de relação ocorre quando analisadas a relação entre a variável antecedente criminal e a deliberação $\left(\chi^{2}=1,39 ; \mathrm{gl}=1 ; \mathrm{p}=0,238\right)$ e a variável ordem das teses e a deliberação $\left(\chi^{2}=0,100 ; \mathrm{gl}=1\right.$; $\mathrm{p}=0,751)$.

Como forma de se testar as hipóteses do estudo foi realizada uma regressão logística binomial, tendo-se como variável dependente a deliberação individual. Foram consideradas variáveis independentes o antecedente criminal e a ordem dos debates e como variáveis antecedentes o desempenho da defesa, o desempenho da promotoria, o número de acertos de argumentos da defesa e o número de acertos de argumentos da promotoria. Este modelo explicou parte da variância da deliberação (Nagelkerke $\mathrm{R}^{2}=0,41$ ) e foram preditores significativos o desempenho da defesa $(\mathrm{B}=0,646 ; \mathrm{p}<0,001)$, o desempenho da promotoria $(\mathrm{B}=-$ $0,708 ; \mathrm{p}<0,001)$ e o número de acertos dos argumentos da defesa $(B=0,450 ; p=0,039)$. Estes dados indicam que a manipulação experimental não surtiu o efeito hipotetizado, refutando $\mathrm{H} 1$ e $\mathrm{H} 2$. Mas os resultados apontam que a avaliação de desempenho das partes é preditora significativa na direção esperada, pois quanto mais bem avaliado o 
desempenho do advogado de defesa maior a tendência dos jurados em absolver e o mesmo ocorre quando da avaliação da promotoria.

Quanto à H2a observou-se que houve um efeito marginalmente significativo no concernente a atribuição interna $(F=3,48 ; p=0,065)$, pois os participantes na condição com antecedentes realizaram maior atribuição interna $(\mathrm{M}=4,78 ; \mathrm{DP}=1,80)$ do que na condição sem antecedentes $(\mathrm{M}=5,36 ; \mathrm{DP}=1,41)$. Esta evidência dá suporte marginal a H2a. Para o teste de H1a foram realizada análises de comparação do desempenho de acertos dos argumentos das partes em função da ordem de apresentação das teses. A análise indicou que não há diferença significativa no número de acertos na recordação de argumentos da defesa em nenhum dos grupos experimentais $(\mathrm{F}=0,472 ; \mathrm{gl}=1 ; \mathrm{p}=0,493)$, bem como no número de acertos na recordação de argumentos da acusação $(\mathrm{F}=0,007 ; \mathrm{gl}=1 ; \mathrm{p}=0,931)$. Esta evidência refuta H1a.

Entretanto, a análise da avaliação subjetiva do grau de certeza da resposta correta aos argumentos, indicou que os participantes tenderam a relatar maior grau de certeza para os argumentos da acusação do que para os argumentos da defesa $(\mathrm{F}=3,958 ; \mathrm{gl}=1 ; \mathrm{p}=0,049)$. Este resultado pode ser compreendido a partir do desempenho superior atribuído ao promotor $(\mathrm{M}=4,51 ; \mathrm{DP}=1,45)$, quando comparado com o desempenho do advogado de defesa $(\mathrm{M}=3,30 ; \mathrm{DP}=1,38)$.

Os resultados do estudo evidenciaram um efeito inesperado do alto grau preditivo do desempenho dos atores que realizaram o papel de acusador e defensor do réu, que pode ser explicado pelo grau elevado de importância dada pelos jurados à postura das partes durante o debate para a deliberação. Vale ressaltar que a apresentação das evidências foi rigorosamente controlada no planejamento dos debates, buscando-se garantir equilíbrio entre os argumentos. Como os argumentos elaborados tinham a possibilidade de anular os elementos causais de explicação utilizados pelos jurados, a avaliação do desempenho acabou sendo uma fonte mais importante de credibilidade, o que pode explicar estes resultados. Como forma de se buscar controle sobre esse elemento definiu-se pela realização de um segundo estudo, que teve como objetivo testar a influência do antecedente criminal, mas controlando-se o efeito do desempenho das partes.

\section{Estudo 2}

O segundo estudo foi realizado com o objetivo de avaliar a influência da forma de apresentação do caso e das teses sobre a deliberação. Com os resultados obtidos no primeiro estudo, especialmente àqueles relativos ao impacto do desempenho dos advogados sobre a deliberação dos jurados, propôs-se um estudo complementar, no qual o vídeo foi substituído por uma transcrição do julgamento, que foi lido pelo experimentador. A manipulação da variável ordem de apresentação das teses foi retirada do segundo estudo. Assim, este segundo estudo consistiu em um delineamento com manipulação de uma variável independente, o antecedente criminal do réu. Este estudo foi desenvolvido seguindo princípios de ética em pesquisa com seres humanos definidos pelo Conselho Nacional de Saúde e pelas diretrizes para ética na pesquisa da Associação Americana de Psicologia. Garantiuse participação voluntária, garantia de sigilo e anonimato dos participantes. O consentimento livre e esclarecido foi realizado de forma oral antes da apresentação dos procedimentos de pesquisa, de forma a garantir compreensão completa dos participantes sobre objetivos do estudo, característica e implicações dos procedimentos da pesquisa. Apenas após a anuência dos participantes voluntários é que se iniciava o procedimento de pesquisa.

\section{Método}

\section{Participantes}

Participaram do segundo estudo 54 estudantes universitários com idade entre 17 e 42 anos $(\mathrm{M}=22,2 ; \mathrm{DP}=6,4)$. Houve maior freqüência de estudantes do curso de Psicologia $(n=25)$ e de mulheres $(n=35)$.

\section{Instrumentos}

$\mathrm{O}$ instrumento utilizado foi o mesmo do primeiro estudo, com as devidas adaptações. A folha de rosto mantevese semelhante, incluindo a foto e a descrição do réu, sendo feitas algumas modificações concernentes às instruções. $\mathrm{Na}$ segunda parte, foi inserida a transcrição do vídeo, contendo a apresentação do caso pelo juiz e os argumentos apresentados pelos advogados. Os discursos foram apresentados na ordem convencional do julgamento: o relato do caso pelo juiz, seguido pelas teses da promotoria e, por fim, do advogado de defesa. A escala de memória não foi utilizada. A terceira folha continha a ficha de deliberação do julgamento simulado, que se manteve igual à versão do primeiro estudo. Por fim, a quarta parte continha a escala de atribuição de causalidade, e as questões sócio-demográficas.

\section{Material \\ Para a coleta dos dados foram utilizados apenas os questionários, sem a necessidade de exibição de vídeo. Os instrumentos foram impressos em impressora Xerox com alta resolução de impressão (1200 DPI).}

\section{Procedimento de coleta de dados}

Com autorização prévia dos professores responsáveis, os questionários foram coletados em três turmas da disciplina Psicologia Social. A abordagem dos grupos se deu de forma similar à do Estudo 1: após uma breve apresentação do consentimento informado, foram lidas as instruções para o procedimento da pesquisa, destacando que, uma vez lida a apresentação do caso em conjunto com a turma, os participantes não poderiam retornar ao texto. $\mathrm{O}$ experimentador procedeu, então, a leitura dos argumentos contidos na segunda página em conjunto com a turma. O preenchimento do questionário procedeu como no primeiro estudo. 


\section{Procedimento de análise dos dados}

Os dados foram analisados como no Estudo 1.

\section{Resultados e Discussão}

As análises indicaram que houve uma tendência maior a absolvição neste estudo, sem uma associação entre a variável antecedente criminal e a deliberação dos jurados $\left(\chi^{2}=0,015\right.$; $\mathrm{gl}=1 ; \mathrm{p}=0,902)$. Os dados também indicaram que não houve diferenças na avaliação de atribuição nos grupos experimentais $(\mathrm{F}=0,530 ; \mathrm{gl}=1 ; \mathrm{p}=0,470)$, mas a amostra deste estudo tendeu a atribuir maior internalidade ao comportamento do réu $(\mathrm{M}=2,56 ; \mathrm{DP}=1,25)$ se comparada a amostra do Estudo 1 $(\mathrm{M}=5,06 ; \mathrm{DP}=1,64)$.

Uma análise comparando a tendência de deliberação de ambos os estudos demonstrou que a amostra do Estudo 2 tendeu a absolver o réu mais do que a amostra do Estudo 1 $\left(\chi^{2}=5,13 ; \mathrm{gl}=1 ; \mathrm{p}=0,023\right)$. No Estudo 1,75 jurados condenaram o réu, contra 48 que o absolveram. No Estudo 2, 23 jurados condenaram, contra 31 que absolveram. Este resultado indica um efeito importante sobre a forma de apresentação do caso, que inverte a tendência de deliberação dos jurados. Isto tem uma implicação relevante para os estudos experimentais de tribunal simulado em nosso contexto.

\section{Considerações finais}

O estudo da psicologia da deliberação legal é uma atividade fundamental para ser desenvolvida em nosso contexto cultural e jurídico-processual. Este trabalho é uma primeira ação na tentativa de se estudar empiricamente estes fatores a partir de um referencial teórico e metodológico da psicologia social experimental. Neste intuito se ressalta que o presente trabalho cumpriu seu propósito.

Ainda que não tenha sido observada corroboração das hipóteses elaboradas não se deve descartar a relevância que processos sócio-cognitivos têm sobre a deliberação dos jurados. No presente trabalho observou-se um efeito marginalmente significativo da atribuição interna na condição de antecedentes, o que denota que este fator pode ter relevância no estabelecimento dos nexos de causalidade no processo de tomada de decisões do jurado. Este resultado deve servir como motivador para o desenvolvimento de novos estudos que busquem testar a influência dos processos causais de explicação do comportamento no processo decisório do jurado. Uma possibilidade de investigação seria a aplicação de modelos causais (Dela-Coleta \& Dela-Coleta, 2006) ou com a aplicação de estratégias metodológicas apropriadas para o entendimento do efeito do desconto no processo atribucional (Hilton, 2007) neste contexto de deliberação legal. A aplicação de um raciocínio de causalidade da conduta do réu baseada na expectativa de comportamento do alvo, por meio, por exemplo, da criação de um estereótipo, deve ser mais bem investigada neste contexto, por meio do uso de estratégias diversificadas para o teste de hipóteses. Esta pode ser uma contribuição para o próprio modelo da história sumarizada (Pennington \& Hastie, 1988), além de nos permitir compreender como este elemento extralegal exerce influência na decisão do jurado.

Com relação ao efeito da ordem dos debates sobre a acurácia da recordação dos argumentos pode-se depreender que não há diferença para os jurados. Este resultado é importante para a discussão dos aspectos legais da estruturação do código de processo penal brasileiro, que a partir de uma visão constitucionalista do mesmo (Rangel, 2005) pressupõe que a tese da defesa apresentada por último é uma forma de se garantir favorabilidade ao réu. No caso deste estudo simulado isto não foi observado e a inversão dos debates não surtiu qualquer influencia na deliberação, o que não dá suporte a retórica jurídica de que a ordem dos debates interfira na decisão do júri. A partir de uma perspectiva do processo cognitivo de memória a ausência do efeito hipotetizado se deve a vários fatores interferentes, inerentes a um processo de julgamento, como o próprio desempenho das partes durante os debates. Além disto, não é possível se isolar o efeito que a primazia de apresentação dos argumentos tem sobre a recordação, pois a evidência empírica levantada demonstra que não há melhor desempenho dos jurados ao recordar dos argumentos em qualquer uma das condições experimentais.

Este resultado do processo de memorização dos jurados indica a necessidade de uma exploração mais bem elaborada dos modelos de processos cognitivos básicos de memória, como é o caso do ACT, em um contexto aplicado. A melhor exploração destes modelos permitirá o desenvolvimento teórico e metodológico da literatura de psicologia da deliberação legal, permitindo, inclusive o aprimoramento de modelos de tomada de decisões de jurados, como é o caso do modelo da história de Pennington e Hastie (1992).

Um resultado inesperado deste estudo diz respeito à forte influência exercida pelo desempenho das partes na deliberação dos jurados. Os resultados do Estudo 1 indicaram isto e esta tendência foi reforçada pelo que foi encontrado no Estudo 2. É importante ressalvar que este resultado indica que o desempenho das partes exerce um papel relevante no processo de tomada de decisões dos jurados, o que pode ser evidenciado pela maior convicção apresentada na recordação dos argumentos da promotoria, parte mais bem avaliada no desempenho global. É importante ressaltar que este fator exerce um efeito interferente nas variáveis manipuladas, o que pode auxiliar a compreender a ausência de efeitos. De qualquer forma, este elemento deve ser considerado no desenvolvimento de pesquisas de tribunal simulado. Em estudos futuros o desempenho das partes pode ser tratado como uma variável independente ou variações metodológicas que possam controlar a influência desta variável, como a apresentação de gravações de julgamentos reais ou o uso de transcrições em texto.

Este trabalho refere-se a um primeiro esforço para a produção de pesquisa empírica, por meio de tribunal simulado, na psicologia da deliberação legal no contexto cultural 
e jurídico processual do nosso país. Os resultados aqui apresentados trazem poucas conclusões e muitos questionamentos que devem ser respondidos por meio da produção continuada de conhecimentos, com uso de delineamentos metodológicos diversificados, mas sem a perda do rigor da produção científica. Novos estudos devem ser empreendidos de forma a se responder a questões da agenda de pesquisa em psicologia da deliberação legal, como aqueles apontados por Pilati e Silvino (2009). A realização de uma agenda de pesquisa empírica sobre a temática é a estratégia para a criação e estruturação do campo da psicologia da deliberação legal no país, permitindo a produção de conhecimentos e tecnologias sociais para a formação e atuação dos operadores do direito no Brasil.

\section{Referências}

Anderson, J. R. (1983a). The architecture of cognition. Cambridge: Harvard University Press.

Anderson, J. R. (1983b). Problem solving and learning. American Psychologist, 48, 35-44.

Anderson, J. R., \& Pirolli, P. L. (1984). Spread of activation. Journal of Experimental Psychology: Learning, Memory and Cognition, 10, 791-798.

Anderson, C. A., Krull, D. S., \& Weiner, B. (1996). Explanations: Processes and consequences. In E. T. Higgins \& A. W. Kruglanski (Eds.), Social psychology: Handbook of basic principles (pp. 271-296). London: The guilford press.

Anderson, J. R., Fincham, J. M., Qin, Y., \& Stocco, A. (2008). A central circuit of the mind. Trends in cognitive sciences, 12, 136-143.

Anderson, J. R., Bothell, D., Byrne, M. D., Douglass, S., Lebiere, C., \& Qin, Y. (2004). An integrated theory of mind. Psychological Review, 111, 1036-1060.

Brasil, C. N. (2007). Código de processo penal (47a ed., Vol. 3689/1941, pp. 1-497). São Paulo: Saraiva.

Dela-Coleta, J. A., \& Dela-Coleta, M. (2006). Atribuição de causalide: Teoria, pesquisa e aplicações. Taubaté: Cabral Editora e Livraria Universitária.

Diamond, S. S., \& Rose, M. R. (2005). Real juries. Annual Review of Law and Social Sciences, 1, 255-284.

Ellsworth, P. C., \& Mauro, R. (1998). Psychology and law. In D. T. Gilbert, S. T. Fiske, \& G. Lindzey (Eds.), The handbook of social psychology (Vol. 2, pp. 684-732). New York: McGraw-Hill.

Fiske, S. T. (1998). Stereotyping, prejudice, and discrimination. In D. T. Gilbert, S. T. Fiske, \& G. Lindzey (Eds.), The handbook of social psychology (Vol. 2, pp. 357-411). New York: McGraw-Hill.

Fiske, S. T., \& Taylor, S. E. (2008). Social cognition: From brains to culture. New York: McGraw-Hill.

Gigerenzer, G., Todd, P. M., \& Group, A. (1999). Simple heuristics that make us smart. New York: Oxford University Press.
Hair, J. F., Anderson, R. E., Tatham, R. L., \& Black, W. C. (2005). Análise multivariada de dados (5a ed.). Porto Alegre: Bookman.

Hilton, D. (2007). Causal explanations: From social perception to knowledge-based causal attribution. In A. W. Kruglanski \& E. T. Higgins (Eds.), Social psychology: Handbook of basic principles (pp. 232-253). New York: The Guilford Press.

Kerr, N. L., \& Bray, R. M. (2005). Simulation, realism and the study of jury. In N. Brewer \& K. D. Williams (Eds.), Psychology and law: An empirical perspective (pp. 322364). New York: Guilford Press.

Köhnken, G., Fiedler, M., \& Möhlenbeck, C. (2001). Psychology and law. In A. Tesser \& N. Schwarz (Eds.), Blackwell handbook of social psychology: Intraindividual processes (Vol. 1, pp. 547-568). Oxford: Blackwell.

Kunda, Z., \& Thagard, P. (1996). Forming impressions from stereotypes, traits, and behaviors: A parallel-constraintsatisfaction theory. Psychological Review, 103, 284-308.

Levett, L. M., Danielsen, E. M., Kovera, M. B., \& Cutler, B. L. (2005). The psychology of jury and juror decision making. In N. Brewer \& K. D. Williams (Eds.), Psychology and law: An empirical perspective (pp. 365406). New York: Guiford Press.

Matlin, M. W. (2004). Psicologia cognitiva. Rio de Janeiro: LTC.

Operario, D., \& Fiske, S. T. (2001). Stereotypes: Content, structures, processes and context. In R. Brown \& S. Gaertner (Eds.), Blackwell handbook of social psychology: Intergroup processes (Vol. 1, pp. 22-44). Oxford: Blackwell.

Pennington, N., \& Hastie, R. (1988). Explanation-based decision making: Effects of memory structure on judgment. Journal of Experimental Psychology: Learning, memory and cognition, 14, 521-533.

Pennington, N., \& Hastie, R. (1992). Explaining the evidence: Tests of the story model for juror decision making. Journal of Personality and Social Psychology, 62, 189-206.

Pereira, M. E. (2002). Psicologia social dos estereótipos. São Paulo: EPU.

Pilati, R., \& Silvino, A. M. D. (2009). Psicologia e deliberação legal no tribunal do júri brasileiro: Proposição de uma agenda de pesquisa. Psicologia: Reflexão e Crítica, 22, 277-285.

Quinn, K. A., Macrae, C. N., \& Bodenhausen, G. V. (2003). Stereotyping and impression formation: How categorical thinking shapes person perception. In M. Hogg \& J. Cooper (Eds.), The SAGE handbook of social psychology (pp. 87-109). London: SAGE.

Rangel, P. (2005). Tribunal do júri: Visão linguística, histórica, social e dogmática. São Paulo: Lumen Juris.

Studebaker, C., \& Penrod, S. (2005). Pretrial publicity and its influence on juror decision making. In N. Brewer \& K. D. Williams (Eds.), Psychology and law: An empirical perspective (pp. 254-275). New York: Guilford Press. 
Tabachnick, B., \& Fidell, L. S. (2001). Using multivariate statistics. San Francisco: Allyn \& Bacon.

Trope, Y., \& Cooper, J. (2003). Attribution and person perception. In M. Hogg \& J. Cooper (Eds.), SAGE handbook of social psychology (pp. 190-208). London: SAGE.

Tyler, T. R., \& Jost, J. T. (2007). Psychology and the Law: Reconciling normative and descriptive accounts of social justice and system legitimacy. In A. W. Kruglanski \& E. T. Higgins (Eds.), Social psychology: Handbook of basic principles (pp. 807-825). New York: Guilford Press.

Vainsencher, S. A., \& Farias, A. S. d. (1997). Júri popular: Algumas possibilidades de condenação ou absolvição. Revista de Informação Legislativa, 34(133), 17-22.

Williams, K. D., \& Jones, A. (2005). Trial strategy and tactics. In N. Brewer \& K. D. Williams (Eds.), Psychology and law: An empirical perspective (pp. 276-321). New York: Guilford Press.

Ronaldo Pilati é Professor Adjunto do Instituto de Psicologia da Universidade de Brasília, campus Darcy Ribeiro.

Alexandre Magno Dias Silvino é Professor Titular do Programa de Pós-graduação e Coordenador do Núcleo de Produção Científica da Faculdade de Ciências Sociais e Tecnológicas.

Marco Akira Miura é mestrando em Psicologia Social pelo Programa de Pós-graduação em Psicologia Social, do Trabalho e das Organizações do Instituto de Psicologia da Universidade de Brasília, bolsista REUNI/CAPES.

Lucas Soares Caldas é graduando em Psicologia pela Universidade de Brasília.

Recebido: 31/08/2009

$1^{a}$ revisão: $14 / 12 / 2009$

$2^{a}$ revisão: 08/03/2010

Aceite final: 08/01/2010 